\title{
A. Watanabe \\ T. Kobashi \\ Lateral gaze disturbance due to cerebral microbleed in the medial lemniscus in the mid-pontine region: a case report
}

Published online: 25 July 2006

C) Springer-Verlag 2006

The online version of the original article can be found at: http://dx. doi.org/10.1007/s00234-005-1441-1.

A. Watanabe $(\triangle) \cdot$ T. Kobashi Department of Neurosurgery,

Kasaoka Daiichi Hospital, 1945 Yokoshima,

Kasaoka, Okayama, 714-0043, Japan e-mail: akira-watanabe@kasaoka-d-hp.or.jp

Tel.: +81-865-670211

Fax: +81-865-673131

\section{Neuroradiology (2005) 47: 908-911}

In Fig. 1c the arrow and the arrowhead were incorrectly positioned. The corrected figure is shown here.

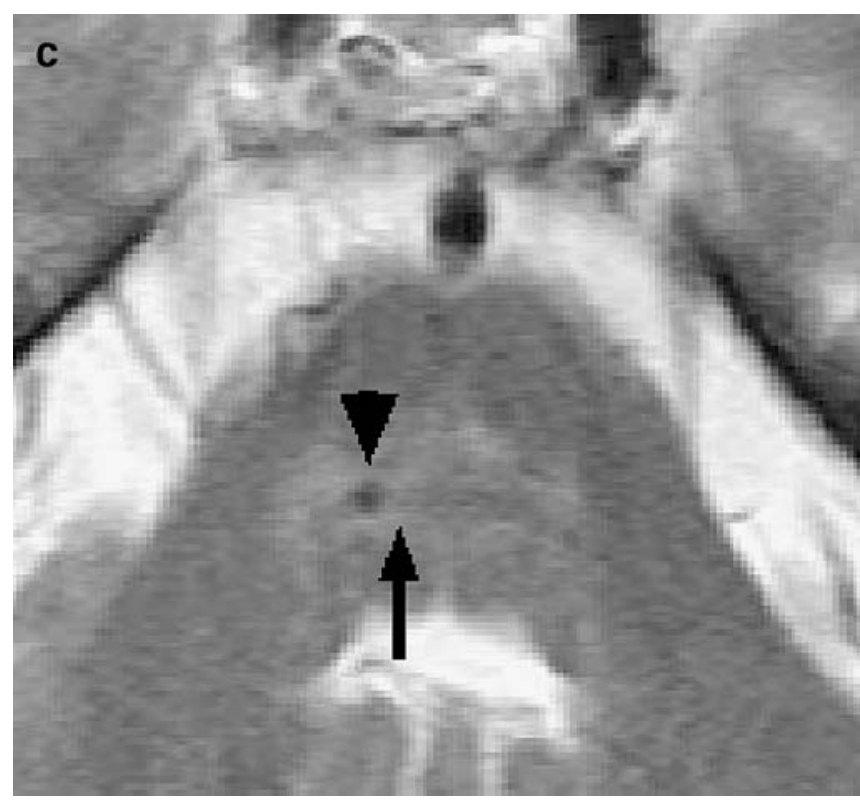

Fig. 1 a A first gradient-echo T2*-weighted MR image showing no cerebral microbleed in the mid-pontine region (23 April 2003). b A second gradient-echo T2*-weighted MR image showing a new cerebral microbleed in the mid-pontine region (15 April 2004). c The cerebral microbleed (arrowhead) was found in the medial lemniscus of the right side (arrow) on T2-weighted MR imaging 